\title{
GC/MS, FTIR and NMR Studies for the Identification and Characterization of Clopidogrel Bisulfate Degradation Products
}

\author{
Samer Housheh ${ }^{1 *}$, Saleh Trefi ${ }^{1}$, Mohammed Haroun² and Mustafa Fawaz Chehna ${ }^{1}$ \\ ${ }^{1}$ Department of Quality Control and Pharmaceutical Chemistry, Faculty of Pharmacy, University of Aleppo, Syrian Arab Republic. \\ ${ }^{2}$ Department of Quality Control and Pharmaceutical Chemistry, Faculty of Pharmacy, University of Tishreen, Syrian Arab Republic.
}

\begin{abstract}
Clopidogrel Bisulfate is a thienopyridine derivative. The separation, identification and degradation of Clopidogrel Bisulfate under hydrolytic and oxidative stress conditions according to the International Conference on Harmonization (ICH) guideline Q1A (R2) was performed. TLC using ( $\mathrm{n}$-hexan:tetrahydrofuran)(1:1 v/v) as a mobile phase was used to separate the degradation products. Three compounds were isolated then analyzed using RP-HPLC which showed a purity of $99 \%$. Mass fragmentation pathway of the compounds were first established with the help of GC/MS studies. Then, the degradation products were subjected to FTIR and $1 \mathrm{H}$ NMR studies. The obtained data were employed to characterize the degradation products and assign structures. The degradation products were identified as (S)-2-(2-chlorophenyl)-2-(6,7-dihydrothieno[3,2-c]pyridin-5(4H)-yl) acetic acid in acidic and basic media, 2-(2-chlorophenyl)-2-oxoacetic acid and 4,5,6,7-tetrahydrothieno [3,2-c] pyridine in oxidative medium.
\end{abstract}

Key words: Clopidogrel degradation products, FTIR, GC/MS, NMR, Stress studies.

\section{INTRODUCTION}

Clopidogrel hydrogen sulfate, methyl $(+)-(\mathrm{S})-\alpha-($ o - chlorophenyl $)-6,7$ dihydrothieno $[3,2-c]$ pyridin- $5(4 \mathrm{H})$-acetate hydrogen sulfate, is a novel thienopyridine derivative that irreversibly blocks adenosine diphosphate (ADP) and is important in platelet aggregation, the cross-linking of platelets by fibrin. Clopidogrel bisulphate (Figure 1) is chemically related to Ticlopidine with superior side effects profile and dosing requirements. ${ }^{1-3}$

The empirical formula of Clopidogrel bisulfate is $\mathrm{C}_{16} \mathrm{H}_{16} \mathrm{ClNO}_{2} \mathrm{~S} \cdot \mathrm{H}_{2} \mathrm{SO}_{4}$ and its molecular weight is $419.9 .^{4}$ The molecule of Clopidogrel contains an asymmetrical carbon leading to the existence of two enantiomers ( $\mathrm{R}$ and $\mathrm{S}$ ). Studies showed that the active compound Clopidogrel is the $\mathrm{S}$ enantiomer. ${ }^{5,6}$ Clopidogrel free base was unstable due to a labile proton in the chiral center and was susceptible to racemization and hydrolysis of methyl ester group.,
It is marketed by Bristol-Myers Squibb and Sanofi- Aventis under the trade name Plavix $^{\circledR}$, a Plavix tablet contains $75 \mathrm{mg}$ of Clopidogrel bisulfate. $^{3}$

Characterization of Clopidogrel bisulfate degradation under solid stress conditions was performed in previous literature, ${ }^{8}$ determination of Clopidogrel bisulfate in active pharmaceutical ingredient by chromatography has also been revealed,' a new study for the identification and characterization of a principle oxidation impurity in Clopidogrel drug substances and drug product was conducted, ${ }^{10}$ for the quantitative determination of Clopidogrel bisulfate active metabolite in human plasma an LC/ MS method was used, ${ }^{11}$ and an LC method for the determination of Clopidogrel in pharmaceutical preparations wasvalidated. ${ }^{12}$ Simultaneous determination of Clopidogrel and Aspirin in pharmaceutical dosage form was mentioned ${ }^{13}$ and RP-HPLC was used
Submission Date :09-01-2015 Revision Date : :29-1-2015 Accepted Date : :05-02-2015

DOI: $10.5530 /$ ijper.49.4.1 Correspondence Address Dr. S Housheh Department of Quality Control and Pharmaceutical Chemistry,

Faculty of Pharmacy, University of Aleppo, Syrian Arab Republic

E-mail:samerhousheh@ hotmail.com

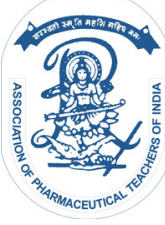

www.ijper.org 


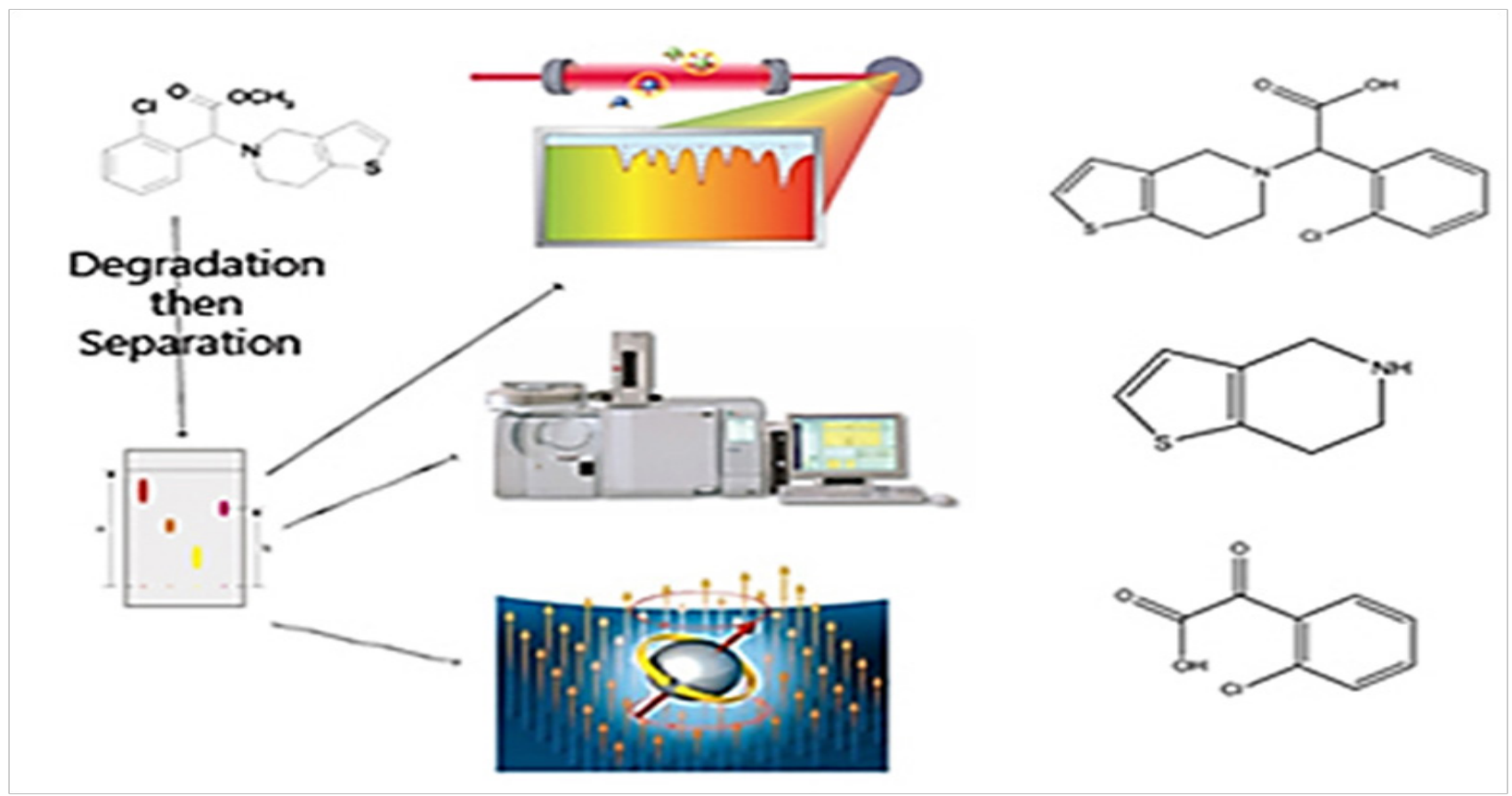

\section{Graphical abstract}

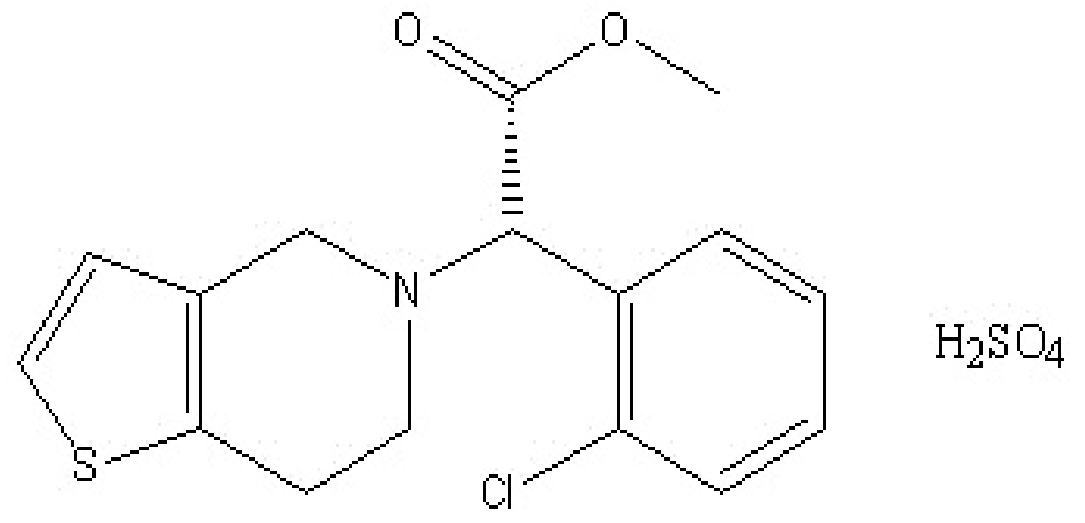

Figure 1: Structural formula of Clopidogrel bisulphate
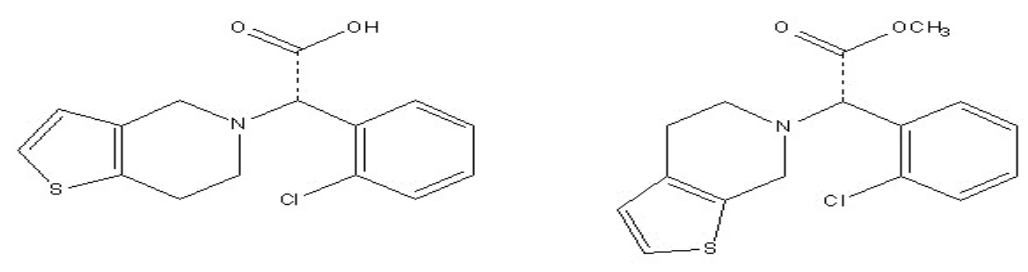

Clopidogrel Related Compound -A

Clopidogrel Related Compound $-\mathrm{B}_{1}$
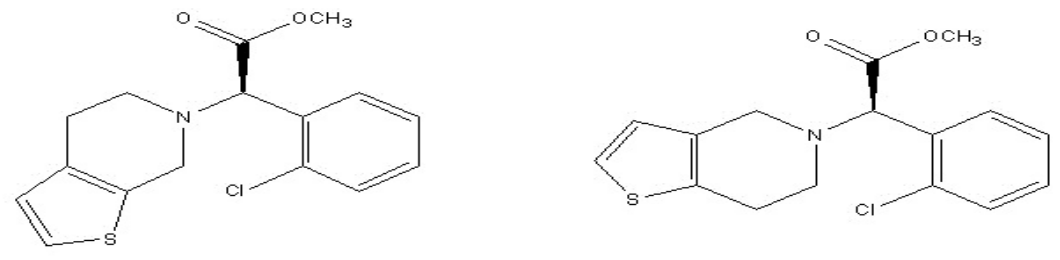

Clopidogrel Rel ated Compound $-\mathrm{B}_{2}$

Clopidogrel Related Compound -C

Figure 2: Structural Formula of known Related Compounds of Clopidogrel17 


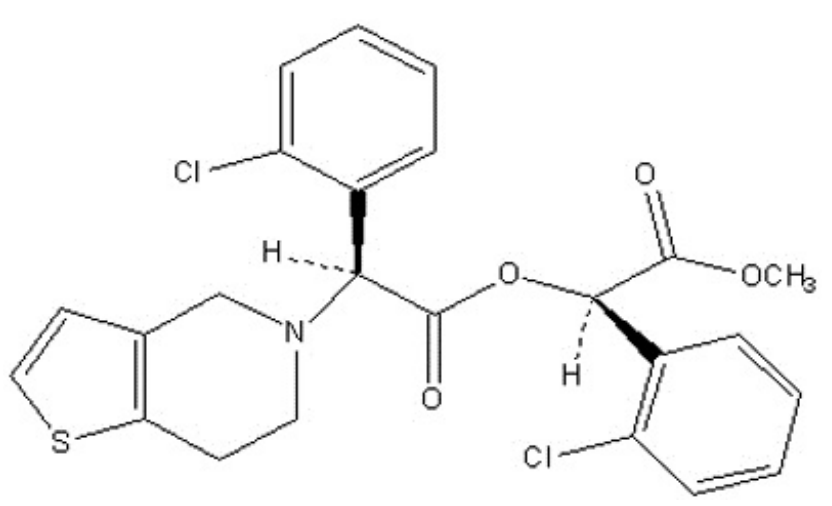

Figure 3: Structural Formula of Related Compound D of Clopidogrel

for the analysis of aspirin and Clopidogrel bisulfate in combination. ${ }^{14}$

Recently, the non-enzymatic and enzymatic chiral inversion of Clopidogrel has been investigated in vitro using ${ }^{1} \mathrm{H}-\mathrm{NMR}$ and a chiral HPLC procedure ${ }^{15}$ For the analysis of the carboxylic acid metabolite of Clopidogrel in plasma and serum a GC-MS method has also been reported. ${ }^{16}$

United States Pharmacopeia-30 (USP-30) ${ }^{17}$ has enumerated related substance method for Clopidogrel tablets in their monograph, the known related compounds of Clopidogrel were given in Figure 2. In addition, British pharmacopeia 2013 has mentioned a related compound named D, as shown in Figure $3{ }^{18}$ Also literature survey revealed that four impurities of Clopidogrel have been already identified. ${ }^{12,19}$

Though these methods already exist in the literature, none of the methods carried out studies to isolate and characterize degradation products of Clopidogrel bisulfate formed by hydrolysis or oxidation under stress condition according to ICH. An attempt was made towards isolation and characterization of degradation products. Therefore, an endeavor of the present study was to decompose the drug under hydrolytic and oxidation conditions, to resolve the products on preparative TLC and to characterize the major products by NMR, GC/ MS and FTIR studies.

\section{MATERIALS AND METHODS}

\section{Chemicals}

Clopidogrel bisulfate was obtained as gift sample from Al-Razi laboratories (Aleppo, Syria) and was used without further purification. Analytical reagent grade hydrogen peroxide $\left(\mathrm{H}_{2} \mathrm{O}_{2}\right)$. Sodium hydroxide $(\mathrm{NaOH})$ was purchased from Hi Media (Mumbai, India). Hydrochloric acid $(\mathrm{HCl})$, Methanol, Dichloromethan, n-hexan, and tetrahydrofuran were supplied by Merck.

\section{APPARATUS AND EQUIPMENT}

\section{Analytical HPLC was performed as mentioned in our previous study..$^{20}$}

\section{GC-MS}

GC-MS analyses were performed on Shimadzu -GCMSQP2010 Plus device equipped with META-5X column (30.0 m X $0.32 \mathrm{~mm} \mathrm{X} 0.25 \mathrm{~mm}$ ), carrier gas was $\mathrm{He}$, and gas flow rate $1.27 \mathrm{ml} / \mathrm{min}$. Mass spectra were obtained by electron impact (EI) ionization at $70 \mathrm{eV}$ with an emission current of $400 \mathrm{~mA}$. The scan time was $1 \mathrm{~s}$ and the scan range was $\mathrm{m} / \mathrm{z} 29-600$. The ion source temperature was maintained at $280^{\circ} \mathrm{C}$. The identity confirmed by fragmentation pattern and by NIST \&WILEY mass spectral libraries. The temperature program was as follows:

- $80^{\circ} \mathrm{C}$, hold for $5 \mathrm{~min}$;

- Temperature rise from $80^{\circ} \mathrm{C}$ to $200^{\circ} \mathrm{C}$ at a rate $20^{\circ} \mathrm{C}$ /min;

- Temperature rise from $200^{\circ} \mathrm{C}$ to $295^{\circ} \mathrm{C}$ at a rate $10^{\circ} \mathrm{C} / \mathrm{min}$ and hold for $5 \mathrm{~min}$.

\section{${ }^{1} H$ NMR Spectroscopy}

About $10 \mathrm{mg}$ of the tested substances were each dissolved in $0.6 \mathrm{~mL}$ of $\mathrm{DMSO}_{-}$and were immediately analyzed by NMR spectroscopy. The one dimensional

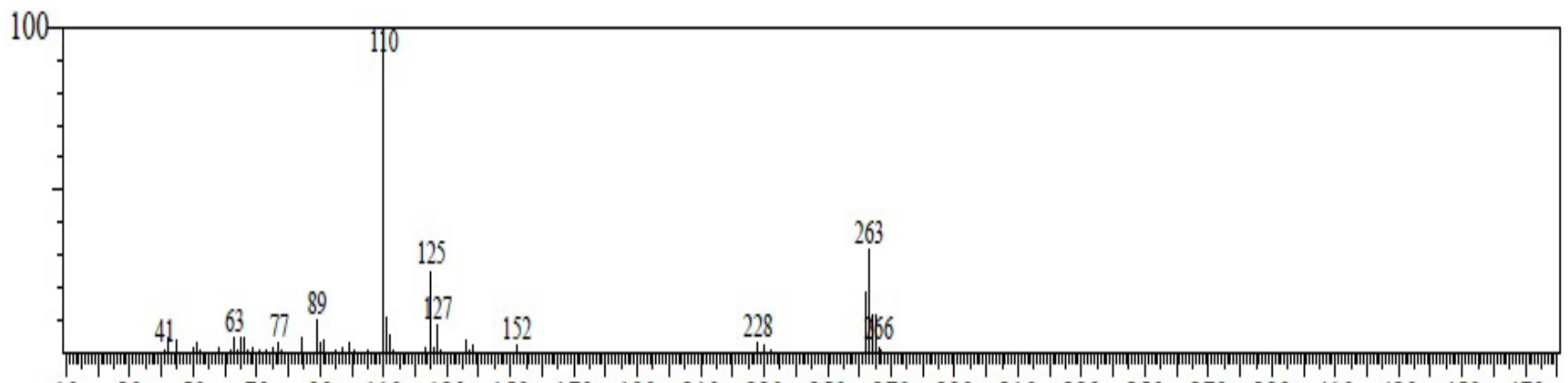

$\begin{array}{llllllllllllllllllllllll}10 & 30 & 50 & 70 & 90 & 110 & 130 & 150 & 170 & 190 & 210 & 230 & 250 & 270 & 290 & 310 & 330 & 350 & 370 & 390 & 410 & 430 & 450 & 470\end{array}$

Figure 4: MS spectrum of compound A (Clopidogrel Acid) 
Table 1: The Mass fragment of compound A (Clopidogrel acid)

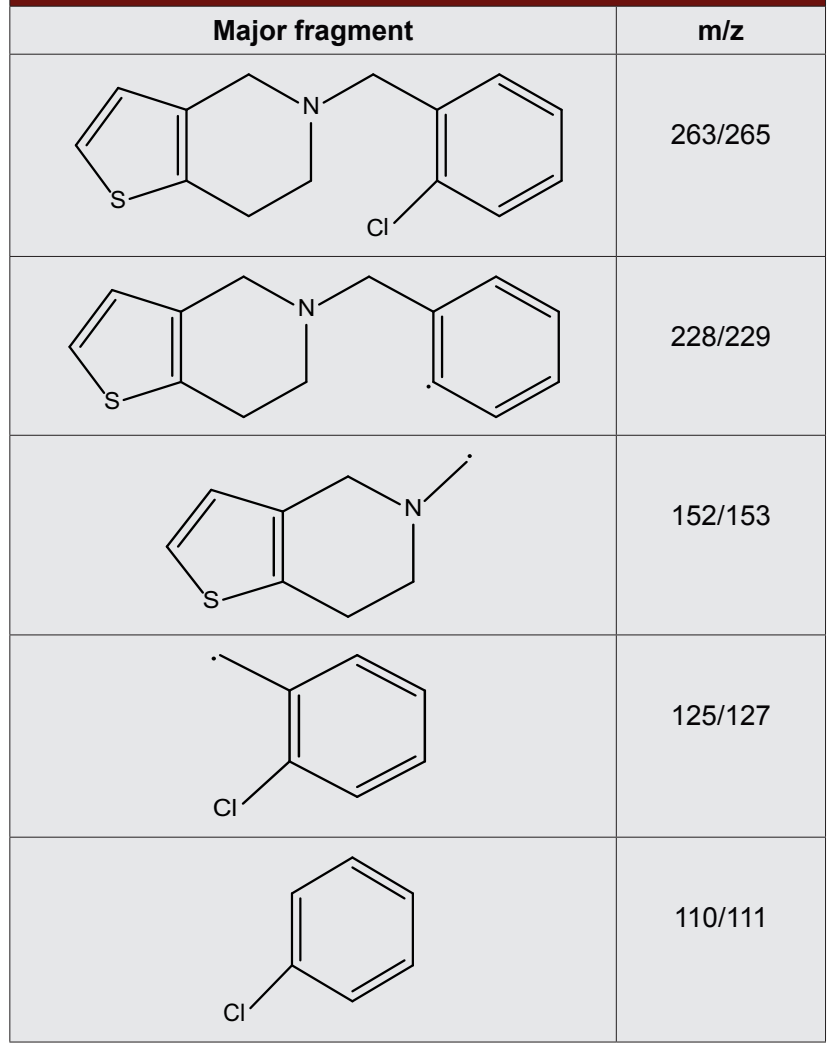

NMR measurements were performed on a BRUKER AVANCE III NMR spectrometer (Bruker, Rheinstetten, Germany) with $400 \mathrm{MHz}$ for ${ }^{1} \mathrm{H}$, employing the manufacturer's pulse programs. The ${ }^{1} \mathrm{H}$ chemical shift values were reported on the $\delta$ scale in ppm. Standard Bruker pulse sequences were applied by running ACD/ Labs (ACD/NMR Processor Academic Edition) software version 12.01 .

\section{IR Spectroscopy}

The IR spectrum was recorded in the solid state as a $\mathrm{KBr}$ disk, and in Nujol as a dispersion medium, using the FT-IR (Bruker, alpha) spectrophotometer, the wave length resolution was set to $4 \mathrm{~cm}^{-1}$, the IR spectrum was collected in a range of $400-4000 \mathrm{~cm}^{-1}$, with Bruker Opus 5.5 software.

\section{Preparative TLC Method}

A mobile phase of ( $\mathrm{n}$-hexan:tetrahydrofuran)(1:1 V) was used, 20 X $20 \mathrm{~cm}$ glass TLC plates coated with (SIL. G. $\left.\mathrm{UV}_{254+360}\right)$ were purchased from MACHEREY-NAGEL GmbH \& Co. KG, Germany.

\section{Preparation of degradation samples of Clopidogrel}

\section{Acid and base degradation}

Accurately weighed $500 \mathrm{mg}$ of Clopidogrel was dissolved in $50 \mathrm{ml}$ of methanol. The drug was subjected to accelerated degradation under acidic and basic conditions by refluxing with $(10 \mathrm{ml}) 1 \mathrm{~N} \mathrm{HCl}$ and $(10 \mathrm{ml}) 1 \mathrm{~N} \mathrm{NaOH}$, respectively, at $70^{\circ} \mathrm{C}$ for a period of 3 and $1 \mathrm{hr}$, respectively. The accelerated degradation in acidic and basic media was performed in the dark in order to exclude the possible degradation effect of light on the drug. ${ }^{19}$

\section{Peroxide degradation}

Accurately weighed $500 \mathrm{mg}$ of drug was dissolved in 50 $\mathrm{ml}$ of methanol. Subsequently, $10 \mathrm{ml}$ of hydrogen peroxide $30.0 \% \mathrm{v} / \mathrm{v}$ was added and the solution was heated in boiling water bath for 1 hour. ${ }^{19}$

\section{Data Analysis}

Structure formulae were generated and processed by Chem Bio Draw Ultra 12.0 Software.

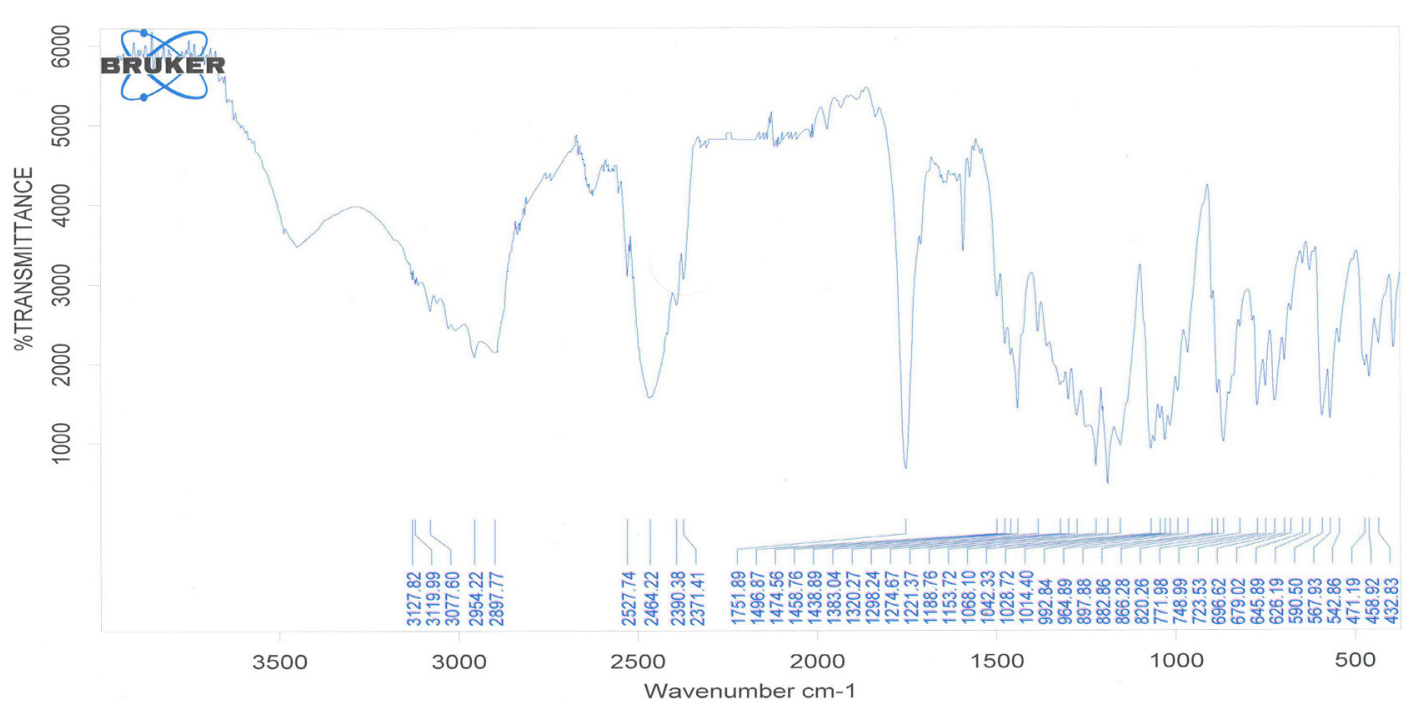




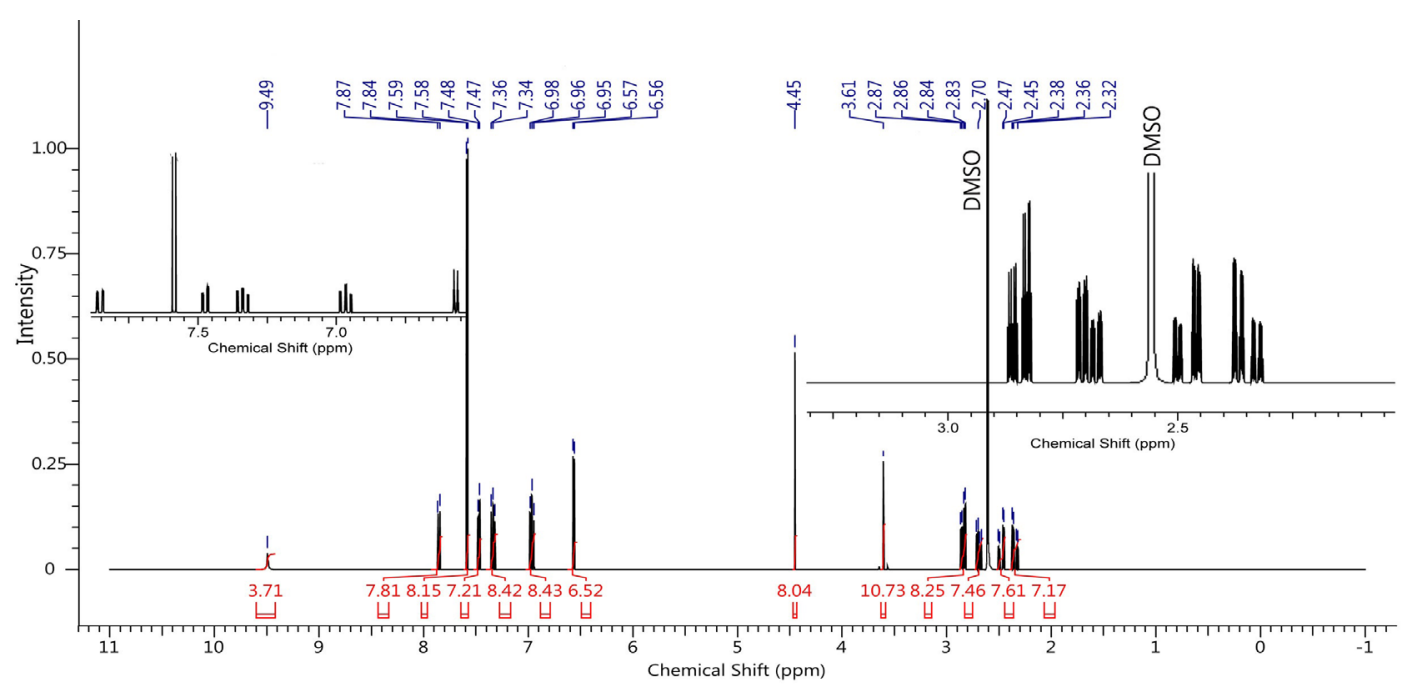

Figure 6: 1H NMR spectrum of compound A (Clopidogrel acid)

\section{RESULTS AND DISCUSSION}

\section{Isolation of Degradation Product(s) by Preparative TLC}

The resultant solutions after acid, base and oxidative degradation were isolated as follows, the aqueous layer was washed with dichloromethane to remove Clopidogrel, then the aqueous layer was subjected to preparative TLC, the bands were visualized using $\mathrm{UV}_{254}$ lamp, the desired band was scratched with a spatula, extracted with methanol which was finally evaporated. The resulted solid was analyzed using RP-HPLC ${ }^{20}$ and the purity of the compound was found to be $99 \%$ which was good enough for carrying out the spectroscopic experiments.

\section{Characterization of the Degradation Product}

Characterization of the compounds was performed using analytical data obtained from IR, GC/MS and ${ }^{1} \mathrm{H}$ NMR spectrum experiments.

\begin{tabular}{|c|c|}
\hline $\begin{array}{c}\text { Table 2: Bands and assignments of compound A } \\
\text { (Clopidogrel acid) }\end{array}$ \\
\hline Frequency $\mathbf{c m}^{-1}$ & Assignment \\
\hline 3450 & OH Carboxylic \\
\hline $2954,3077,3119$ & Chlorophenyl CH Stretch \\
\hline 2464 & C-S-C stretch \\
\hline 1752 & C=O carboxylic \\
\hline 1474,1496 & Chlorophenyl ring stretch \\
\hline 1439,1383 & Pyridine methylene wag \\
\hline 1188 & C-O carboxylic acids \\
\hline 1298,1275 & Methylene twist \\
\hline 1221 & Chlorophenyl C-Cl stretch and bends \\
\hline 1154 & Pyridine ring stretch \\
\hline $1068,1028,1014$, & Pyridine-methylene rock \\
\hline 993 & \\
\hline $749,724,697$ & Chlorophenyl spatial bend \\
\hline
\end{tabular}

\section{Elucidation of the Structure of Degradation Product Resulted from hydrolytic stress Conditions (compound A)}

It was found that there was one degradation product (compound A). The MS, IR, and NMR spectra of product A were recorded. The major Mass fragments obtained by GC-MS analysis are given in Table(1).

As shown in Figure (4) and Table (1) that the main fragment of the product A was m/z: 263/265 which corresponds to Clopidogrel acid when it loses the carboxylic group. Other fragments such as m/z: 125/127 and 110/111 refer to O-chlorophenyl molecule.

FTIR, and ${ }^{1} \mathrm{H}$ NMR spectral data are given in Figure (5), Figure (6) and Tables (2). On the basis of these data it was inferred that the methoxy group of Clopidogrel was not present in compound $\mathrm{A}$.

The degradation product was formed by hydrolysis of ester group of Clopidogrel to form methanol and Clopidogrel acid.

As shown in Figure(5) and table (2), the main functional groups of compound A (Clopidogrel acid) appeared clearly; the absence of ester group, the presence of $\mathrm{OH}$ carboxylic at $3450 \mathrm{~cm}^{-1}$, and the presence of -C-Ocarboxylic at $1188 \mathrm{~cm}^{-1}$.

As shown in Figure 7 , the ${ }^{1} \mathrm{H}$ NMR of compound A show the following data $(400 \mathrm{MHz}$, DMSO-d6) $\delta \mathrm{ppm}$ 2.24 - 2.58 (m, $2 \mathrm{H}, 4) 2.61-2.95$ (m, $2 \mathrm{H}, 3) 3.61$ (ddt, $\mathrm{J}=2.33,1.58,0.75,0.75 \mathrm{~Hz}, 2 \mathrm{H}, 6) 4.44-4.46$ (s, 1 $\mathrm{H}, 10) 6.57$ (d, J=5.10 Hz, $1 \mathrm{H}, 7) 6.97$ (td, J=7.50, 1.20 $\mathrm{Hz}, 1 \mathrm{H}, 15) 7.35$ (t, $1 \mathrm{H}, 16) 7.47$ (d, J=6.30 Hz, $1 \mathrm{H}$, 14) $7.58(\mathrm{~d}, 1 \mathrm{H}, 10) 7.86(\mathrm{~d}, 1 \mathrm{H}, 17) 9.49$ (s, $1 \mathrm{H}, 14)$.

On the basis of these data it was concluded that compound A was (S)-2-(2-chlorophenyl)-2-(6,7-dihydrothi- 


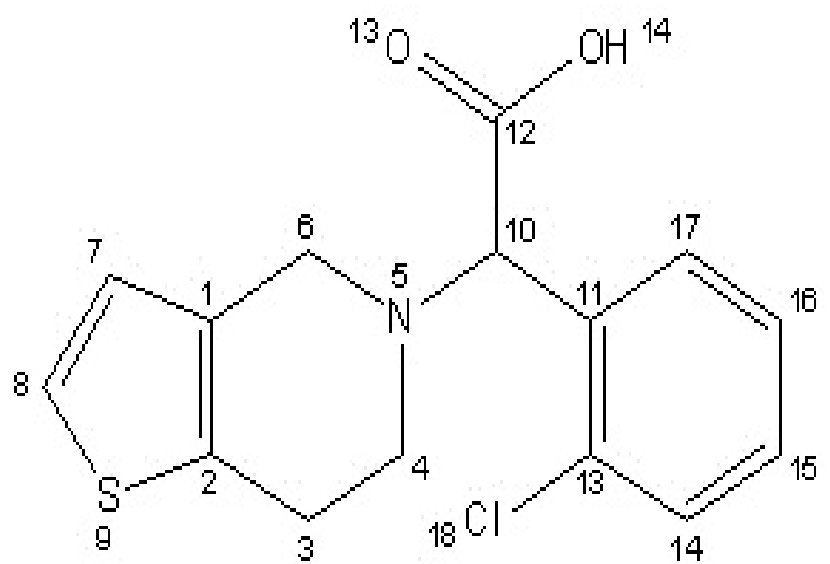

Figure 7: Atom number of compound A (1H NMR)

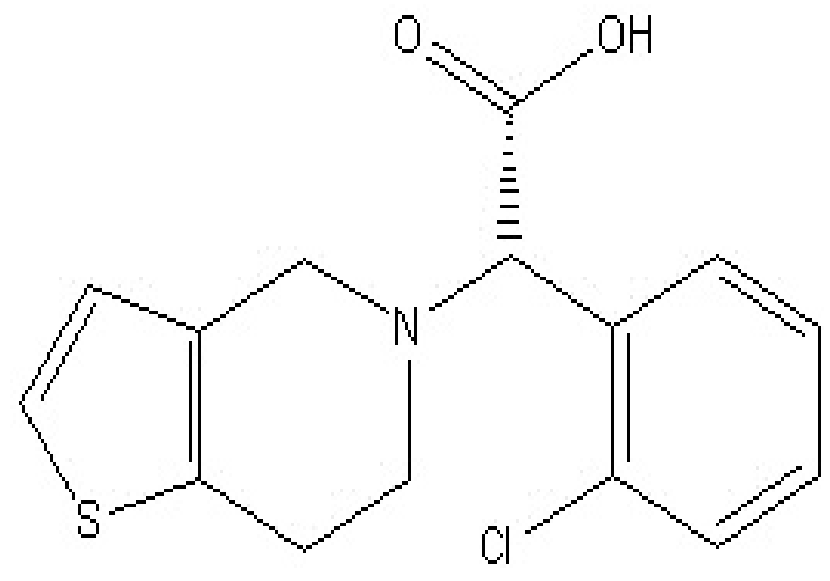

Figure 8: Structure of compound A (Clopidogrel Acid)
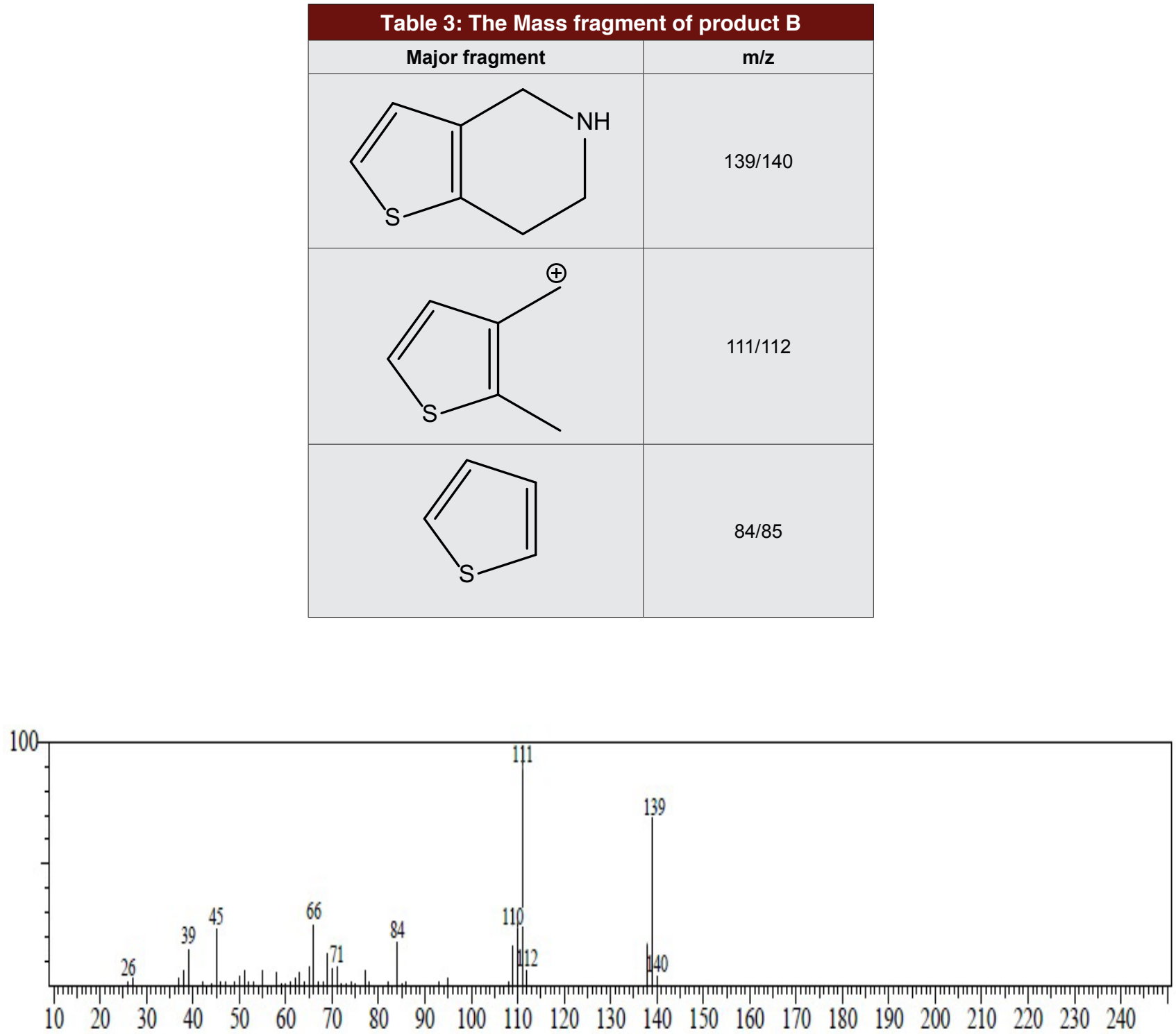

Figure 9: MS of product B 


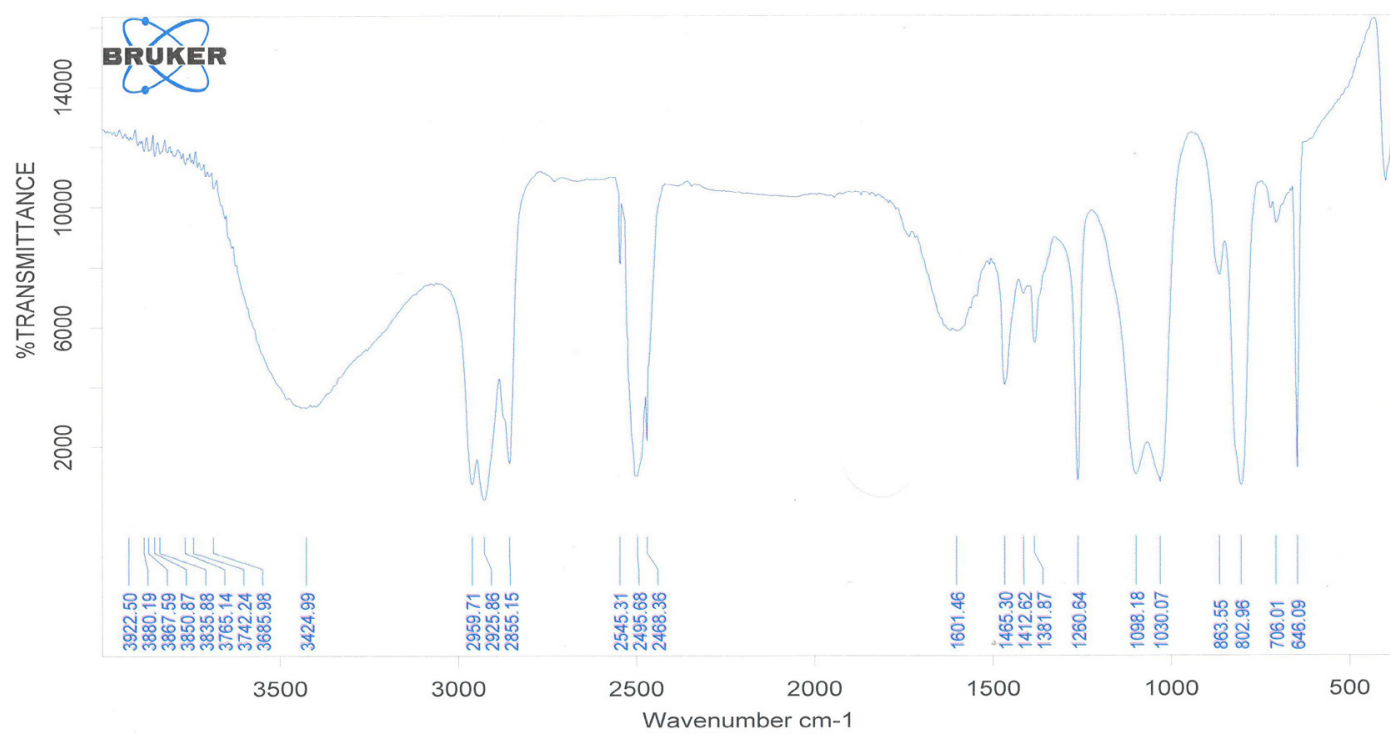

Figure 10: IR spectrum of product $B$

\begin{tabular}{|c|c|}
\hline \multicolumn{2}{|c|}{ Table 4: Bands and assignments of product B } \\
\hline Frequency $\mathbf{c m}^{-1}$ & Assignment \\
\hline 3425 & N-H stretch \\
\hline 2960 & Sym C-H stretch \\
\hline 2926 & C-H stretch \\
\hline 2855 & sym C-H stretch \\
\hline 2496 & C-S-C stretch \\
\hline 1601 & sym wag-stretch \\
\hline 1465 & sym C-H wag \\
\hline 1382 & C-N stretch amine \\
\hline 1261 & Pyridine ring stretch \\
\hline 1098 & C-H wag \\
\hline 1030 & in plane C-C wag \\
\hline 863 & N-H wag \\
\hline 706 & C-H bend \\
\hline 646 & planar ring distortion \\
\hline
\end{tabular}

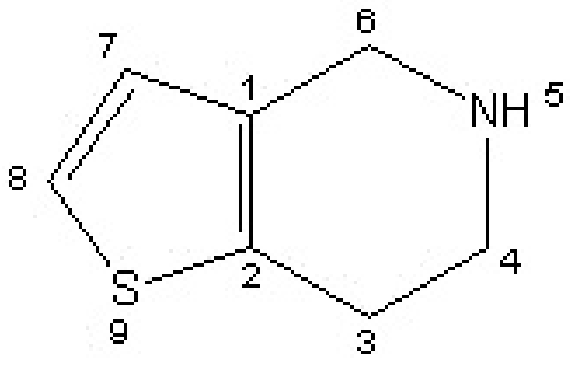

Figure 11: Atom number of compound B ( ${ }^{1} \mathrm{H}$ NMR)

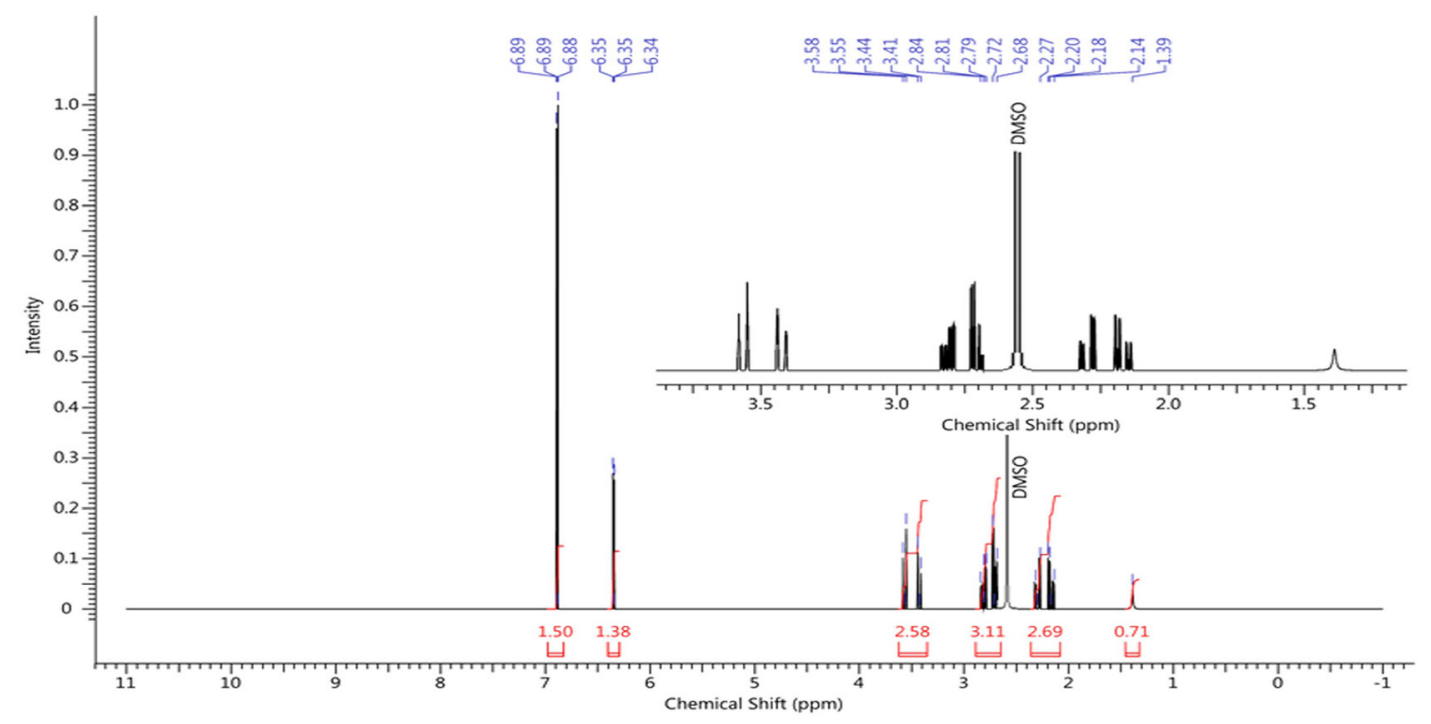

Figure 12: ${ }^{1} \mathrm{H}$ NMR spectrum of compound B 


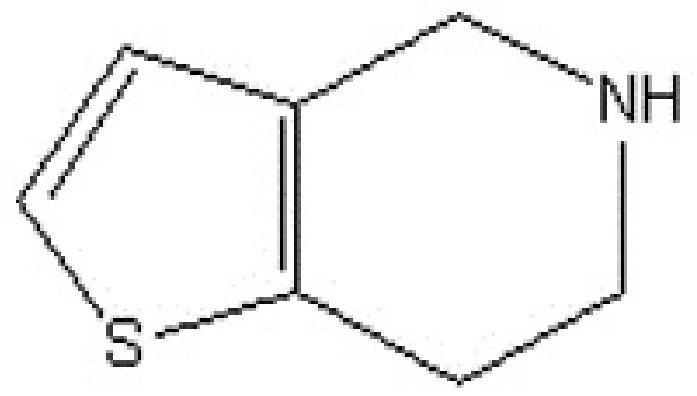

Figure 13: Structure of product B (4,5,6,7-tetrahydrothieno[3,2-c]pyridine)

eno [3,2-c] pyridin-5 (4H)-yl) acetic acid which is (Clopidogrel acid) Figure (8).

\section{Elucidation of the Structure of Degradation Products Resulted from oxidative stress conditions}

It was found that there were two degradation products (compound B and compound C). The MS, IR, and NMR spectra of product $\mathrm{B}$ were recorded. The major Mass fragments for product B is given in Table (3).

The degradation products were formed by fragmentation of Clopidogrel to form product B and product C. GC-MS analysis of product $\mathrm{B}$ revealed a molecular ion peak at $\mathrm{m} / \mathrm{z}: 139 / 140$ and the fragmentation pattern also confirmed the structure given in Figure (9).

IR spectrum and bands and assignments of product B are also shown in Figure (10) and Table (4); respectively.

As shown in Figure(10) and table(4), the main functional groups of product $\mathrm{B}$ appeared clearly; the presence of $\mathrm{N}-\mathrm{H}$ stretch at $3425 \mathrm{~cm}^{-1}$, the aromatic C-H stretch at $2855 \mathrm{~cm}^{-1}$, the presence of C-S-C stretch at $2496 \mathrm{~cm}^{-1}$, the presence of $\mathrm{C}-\mathrm{N}$ stretch and Pyridine ring stretch at $1382,1261 \mathrm{~cm}^{-1}$; respectively.

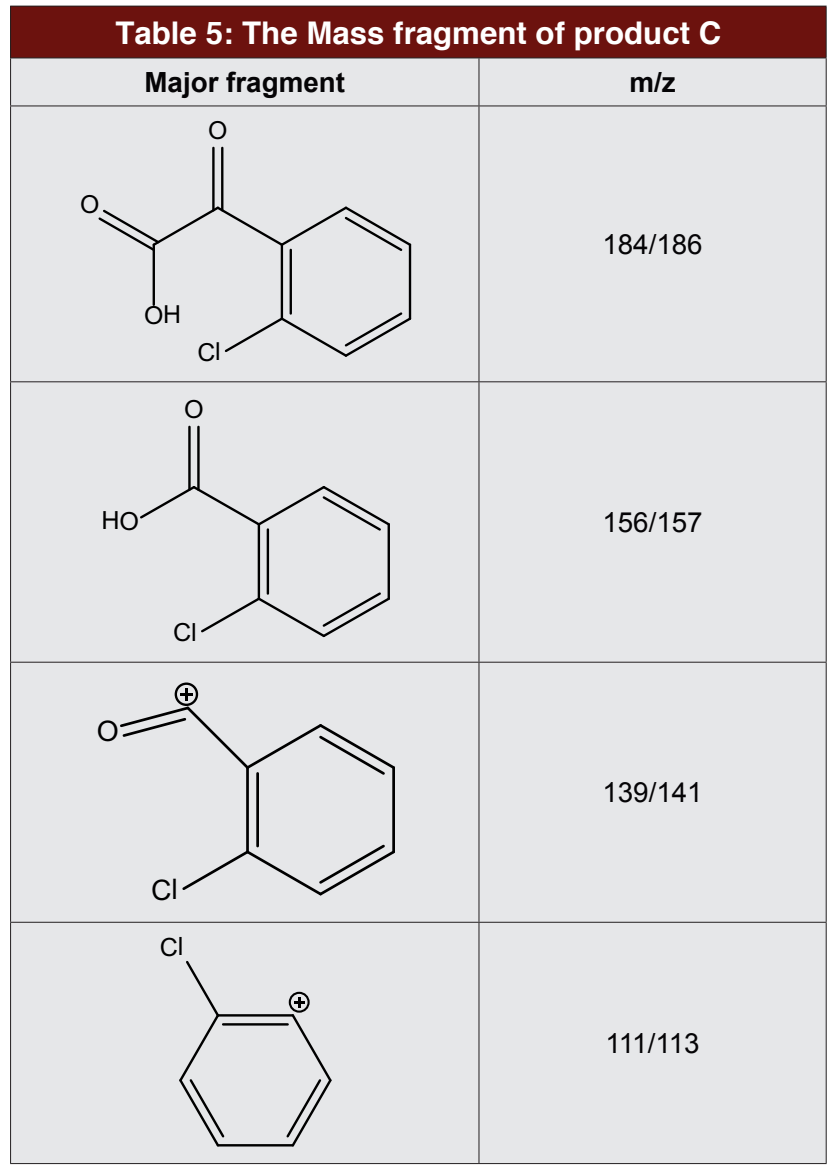

As shown in Figure 11, the ${ }^{1} \mathrm{H}$ NMR spectrum of product $\mathrm{B}$ was (400 MHz, DMSO-d6) $\delta$ ppm 1.39 (s, $1 \mathrm{H}, 5)$ 2.15-2.35 (m, $2 \mathrm{H}, 3)$ 2.7-2.85 (m, $2 \mathrm{H}, 4) 3.4$ - 3.6 (m, 2 H, 6) 6.35 (d, J=5.10 Hz, 1 H, 7) 6.89 (d, J=5.10 Hz, 1 $\mathrm{H}, 8)$. Figure (12).

On the basis of these data it was concluded that the product B was 4,5,6,7-tetrahydrothieno[3,2-c]pyridine Figure (13).

The MS, IR, and NMR spectra of product $C$ were recorded. The major Mass fragments for product $\mathrm{C}$ is given in Table (5).

GC-MS analysis of product $\mathrm{C}$ revealed a molecular ion peak at $\mathrm{m} / \mathrm{z}$ : 184/186 and the fragmentation pattern

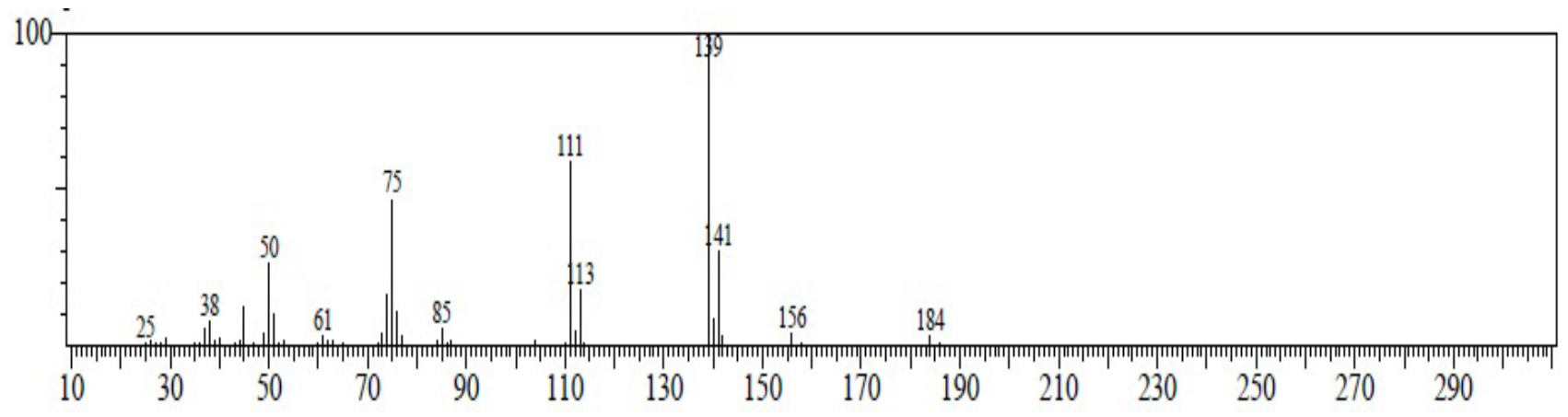

Figure 14: MS of product C 


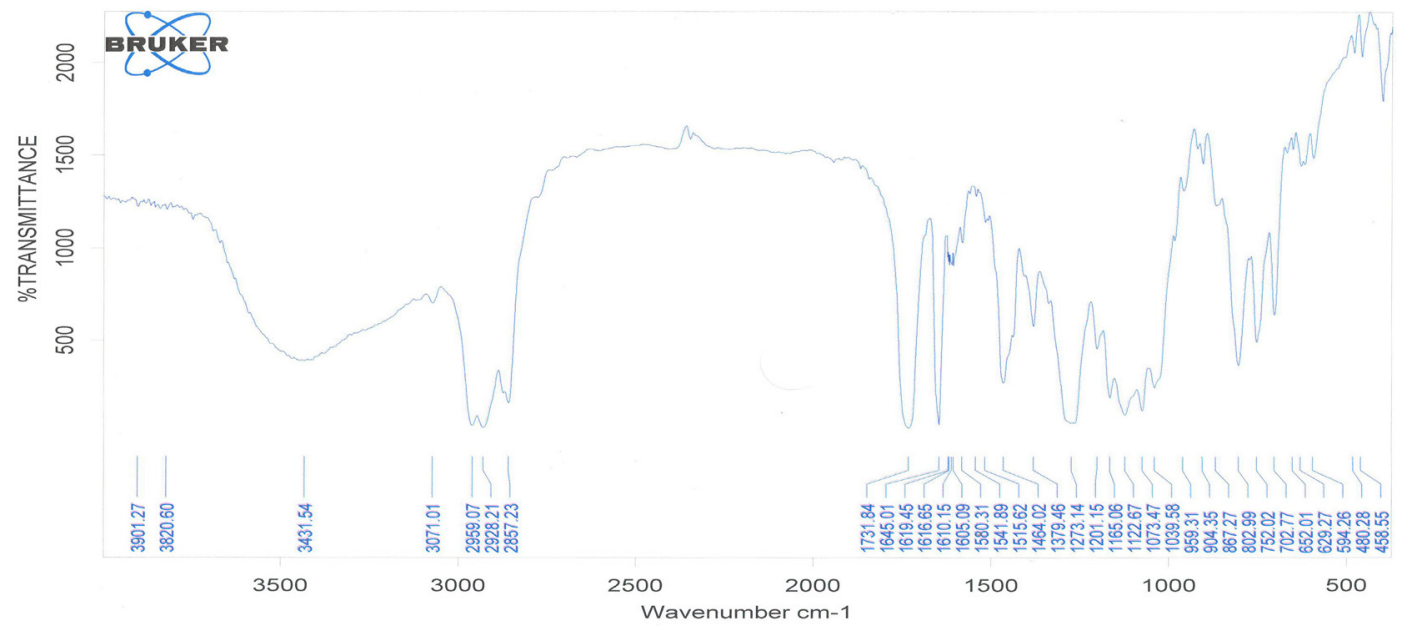

Figure 15: IR spectrum of product C

\section{Table 6: Bands and assignments of product C}

\begin{tabular}{|c|c|}
\hline Frequency $\mathrm{cm}^{-1}$ & Assignment \\
\hline 3431 & OH carboxylic \\
\hline 2959,2928 & Chlorophenyl C-H Stretch \\
\hline 1732 & C=O carboxylic \\
\hline 1645 & C=O ketone \\
\hline 1605,1580 & Chlorophenyl ring stretch \\
\hline 1201 & Chlorophenyl C-Cl bend \\
\hline $803,752,703$ & Chlorophenyl spatial bend \\
\hline
\end{tabular}

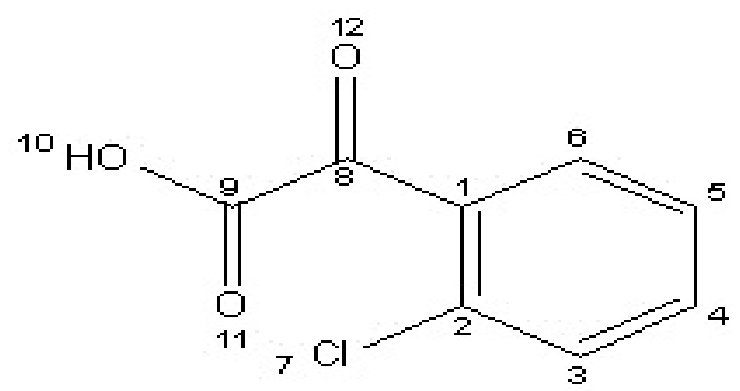

Figure 16: Atom number of compound B ( ${ }^{1} \mathrm{H}$ NMR)

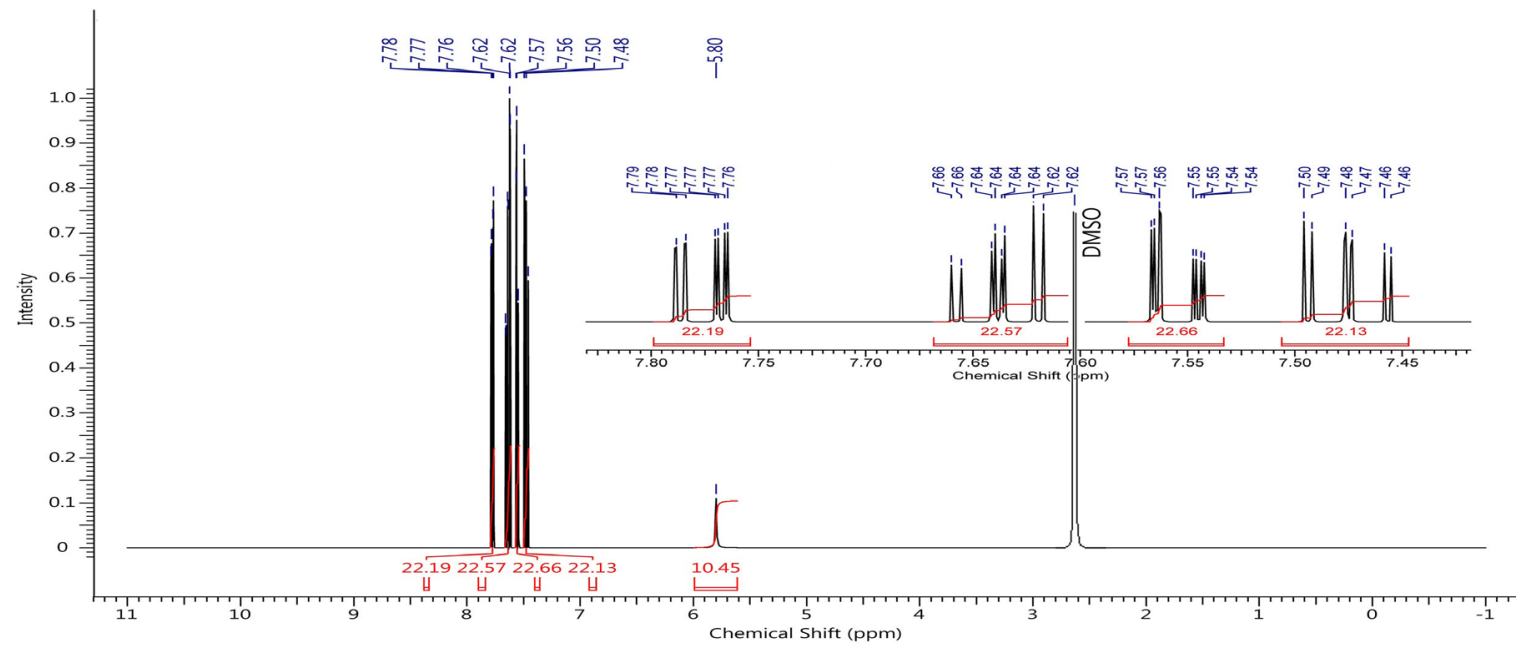

Figure 17: ${ }^{1} \mathrm{H}$ NMR spectrum of compound C

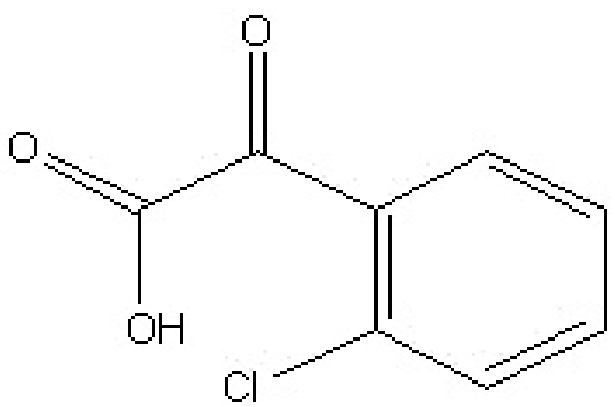

Figure 18: Structure of product C (2-(2-chlorophenyl)-2-oxoacetic acid) 
which is shown in Table (5) also confirmed the structure given in Figure (14).

IR spectrum and bands and assignments of product $C$ are also shown in Figure (15) and Table (6); respectively.

As shown in Figure (15) and table(6), the main functional groups of 2-(2-chlorophenyl)-2-oxoacetic acid appeared clearly; the presence of $\mathrm{OH}$ carboxylic at $3431 \mathrm{~cm}^{-1}$, the aromatic C-H stretch at $2959 \& 2928 \mathrm{~cm}^{-1}$, the presence of $\mathrm{C}=\mathrm{O}$ carboxylic at $1732 \mathrm{~cm}^{-1}$, the presence $\mathrm{C}=\mathrm{O}$ ketone at $1645 \mathrm{~cm}^{-1}$, and $\mathrm{C}-\mathrm{Cl}$ bend $1201 \mathrm{~cm}^{-1}$.

As shown in Figure 16, the ${ }^{1} \mathrm{H}$ NMR spectrum of product $\mathrm{C}$ was $(400 \mathrm{MHz}$, DMSO-d6) $\delta$ ppm 5.80 (s, $1 \mathrm{H}, 10)$ $7.44-7.52$ (td, $1 \mathrm{H}, 4) 7.52$ - 7.59 (dd, $1 \mathrm{H}, 3) 7.60$ - 7.69 (td, $1 \mathrm{H}, 5) 7.77$ (dd, J=7.80 Hz, $1 \mathrm{H}, 6)$, Figure (17).

On the basis of these data it was concluded that product $\mathrm{C}$ was 2-(2-chlorophenyl)-2-oxoacetic acid Figure (18).

\section{CONCLUSION}

The hydrolytic and oxidative degradation product of Clopidogrel bisulfate was isolated by preparative TLC and was characterized using spectroscopic techniques namely NMR, IR, and MS. The degradation products were identified as Clopidogrel acid which is chemically: (S)-2-(2-chlorophenyl)-2-(6,7-dihydrothieno
[3,2-c]pyridin-5(4H)-yl) acetic acid in acidic and basic media, 4,5,6,7-tetrahydrothieno [3,2-c] pyridine and 2-(2-chlorophenyl)-2-oxoacetic acid in oxidative medium.

\section{ABBREVIATIONS}

GC/MS : Gas Chromatography/Mass Spectrometry

FTIR : Fourier transform infrared spectroscopy

NMR : Nuclear magnetic resonance

ICH : International Conference on Harmonization

TLC : :Thin Layer Chromatography

ADP : Adenosine Diphosphate

LC/MS : Liquid Chromatography/ Mass Spectrometry

RP-HPLC : Reversed Phase High Performance Liquid Chromatography

USP : United States Pharmacopoeia

EI : Electron Impact

DMSO-$_{\mathrm{d} \sigma}$ : Deuterated Dimethyl sulfoxide

\section{ACKNOWLEDGEMENTS}

The author would like to thank Al-Razi labs. for providing us Clopidogrel bisulfate, Mr. M. Younes for his technical support in GC-MS analysis, Mr. A. Almadani, Mr. S. Maqsoud and the Atomic Energy Commission for the technical support in ${ }^{1} \mathrm{H}$ NMR analysis.

\section{Highlights of Paper}

- Clopidogrel was subjected to stress degradation according to ICH.

- Degradation products were isolated by preparative TLC.

- GC/MS, FTIR, 1H NMR techniques were used for characterization.

- Structures of Degradation products were elucidated.

\section{Author Profile}

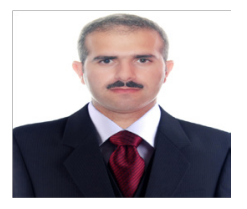

- Samer Housheh, is a Ph.D. candidate at the Department of Quality control and pharmaceutical chemistry, Faculty of pharmacy, University of Aleppo, Syria. My research interests are in the area of chromatographic separation and validation, pharmaceutical analysis, drug profiles.

\section{REFERENCES}

1. Mills DC, Puri R, Hu CJ, Minniti C, Grana G, Freedman MD, et al. Clopidogrel inhibits the binding of ADP analogues to the receptor mediating inhibition of platelet adenylate cyclase. Arteriosc. Thromb. 1992; 12(2): 430-6.

2. Brunton LL. The Pharmacological Basis of Therapeutics. Blood coagulation and anticoagulant, thrombolytic, and anti platelet drugs. New York: The McGraw-Hill Companies; 2006. pp. 1483.

3. http://www.RXlist.com, PLAVIXTM, Rx Med: Pharmaceutical Information, Sanofi/Bristol- Mayers Squibb.

4. http://www.fda.gov/medwatch/safety/2007/May_PI/Plavix_PI.pdf.
5. Savi P, Combalbert J, Gaich C, Rouchon MC, Maffrand JP, et al. The anti aggregating activity of Clopidogrel is due to a metabolic activation by the hepatic cytochrome P450-1A. Thromb. Haemost. 1994; 72(2): 313-7.

6. Pereillo JM, Maftouh M, Andrieu A, Uzabiaga MF, Fedeli O, Savi P, et al. Structure and Stereochemistry of the Active Metabolite of Clopidogrel. Drug Metabol. Dispos. 2002; 30(11): 1288-95.

7. Gomez Y, Adams E, Hoogmartens J. Analysis of purity in 19 drug product tablets containing clopidogrel: 18 copies versus the original brand. J. Pharm. Biomed. Anal. 2004; 34(2): 341-8. 
8. Raijada DK, Prasad B, Paudel A, Shah RP, Singh S. Characterization of degradation products of amorphous and polymorphic forms of Clopidogrel bisulphate under solid state stress conditions. Journal of Pharmaceutical and Biomedical Analysis 2010; 52(3): 332-44.

9. Mohan A, Hariharan M, Vikraman E. Identification and characterization of a principal oxidation impurity in Clopidogrel drug substance and drug product. Journal of Pharmaceutical and Biomedical Analysis 2008; 47(1): 183-9.

10. Vocilkova L, Opatrilova R, Sramek V. Determination of Clopidogrel by Chromatography. Current Pharmaceutical Analysis 2009; 5(4): 424-31.

11. Takahashi M, Pang H, Kawabata K, Farid N. Quantitative determination of Clopidogrel active metabolite in human plasma by LC-MS/MS. Journal of Pharmaceutical and Biomedical Analysis 2008; 48(4): 1219-24.

12. MitakosA, Panderi I. A validated LC method for the determination of Clopidogrel in pharmaceutical preparations. J Pharm. Biomed. Anal. 2002; 28(3): 431-8.

13. Mishara SP, Dolly A. Simultaneous determination of Clopidogrel and aspirin in pharmaceutical dosage forms. Indian. J. Pharm. Sci. 2006; 68(3): 365-8.
14. Mishara SP, Dolly A. RP-HPLC analysis of aspirin and Clopidogrel bisulfate in combination. Indian J.Pharm. Sci. 2005; 67(4): 491-3.

15. Reist M, Roy-de Vos M, Montseny JP, Mayer JM, Carrupt PA, Berger Y, et al. Very slow chiral inversion of Clopidogrel in rats: a pharmacokinetic and mechanistic investigation. Drug Metab. Disp. 2000; 28(12): 1405-10.

16. Lagorce P, Perez $\mathrm{Y}$, Ortiz J, Necciari J, Bressole F. Assay method for the carboxylic acid metabolite of Clopidogrel in human plasma by gas chromatography-mass spectrometry. J. Chromatogr. Biomed. Appl. 1998; 720(1): 107-17.

17. United states Pharmacopoeia 2006; 30(2): 1802-13.

18. British pharmacopeia, Clopidogrel bisulphate, Ph. Eur. Monograph; 2013. 2531.

19. Agrawal H, Kaul N, Paradkar AR, Mahadik KR. Stability indicating HPTLC determination of Clopidogrel bisulphate as bulk drug and in pharmaceutical dosage form Talanta 2003; 61(5): 581-9.

20. Housheh S, Daoud A, Trefi S, Haroun M, Chehna MF. Optimization of RPHPLC Assay for Pharmaceutical Analysis of Clopidogrel. International Journal of Pharmaceutical Sciences and Nanotechnology 2014; 7(1): 2371-6. 